University of Nebraska - Lincoln

DigitalCommons@University of Nebraska - Lincoln

\title{
Phytosterol stearate esters elicit similar responses on plasma lipids and cholesterol absorption but different responses on fecal neutral sterol excretion and hepatic free cholesterol in male Syrian hamsters
}

\author{
Mark M. Ash \\ University of Nebraska-Lincoln, Markash@gmail.com \\ Jiliang Hang \\ University of Nebraska-Lincoln, \\ Patrick Dussault \\ University of Nebraska-Lincoln, pdussault1@unl.edu \\ Timothy P. Carr \\ University of Nebraska - Lincoln, tcarr2@unl.edu
}

Follow this and additional works at: https://digitalcommons.unl.edu/chemistrydussault

Part of the Chemistry Commons

Ash, Mark M.; Hang, Jiliang; Dussault, Patrick; and Carr, Timothy P., "Phytosterol stearate esters elicit similar responses on plasma lipids and cholesterol absorption but different responses on fecal neutral sterol excretion and hepatic free cholesterol in male Syrian hamsters" (2011). Patrick Dussault Publications. 11.

https://digitalcommons.unl.edu/chemistrydussault/11

This Article is brought to you for free and open access by the Published Research - Department of Chemistry at DigitalCommons@University of Nebraska - Lincoln. It has been accepted for inclusion in Patrick Dussault Publications by an authorized administrator of DigitalCommons@University of Nebraska - Lincoln. 


\title{
Phytosterol stearate esters elicit similar responses on plasma lipids and cholesterol absorption but different responses on fecal neutral sterol excretion and hepatic free cholesterol in male Syrian hamsters
}

\author{
Mark M. Ash, ${ }^{1}$ Jiliang Hang, ${ }^{2}$ Patrick H. Dussault, ${ }^{2}$ Timothy P. Carr ${ }^{1}$ \\ 1. Department of Nutrition and Health Sciences, University of Nebraska-Lincoln, Lincoln, Nebraska 68583-0806, USA \\ 2. Department of Chemistry, University of Nebraska-Lincoln, Lincoln, Nebraska 68583-0304, USA \\ Corresponding author - T. Carr, tel 402 472-7940, fax 402 472-1587, email tcarr2@unl.edu
}

\begin{abstract}
The dietary impact of specific phytosterols incorporated into phytosterol fatty acid esters has not been elucidated. Therefore, we tested the hypothesis that phytosterol esters containing different sterol moieties (sitosterol, sitostanol, or stigmasterol) but the same fatty acid moiety (stearic acid) produce different effects on cholesterol metabolism. Male Syrian hamsters were fed sitosterol, sitostanol, and stigmasterol stearate esters ( $25 \mathrm{~g} / \mathrm{kg}$ diet $)$ in an atherogenic diet containing cholesterol $(1.2 \mathrm{~g} / \mathrm{kg})$ and coconut oil $(80 \mathrm{~g} / \mathrm{kg})$. The phytosterol stearates produced no decrease in cholesterol absorption or plasma non-high-density lipoprotein cholesterol despite a reduction in liver free cholesterol in hamsters fed both sitosterol and sitostanol stearate diets. In addition, sitosterol stearate significantly increased fecal esterified and total neutral sterol excretion. Stigmasterol stearate did not differ from control in neutral sterol excretion, plasma lipids, or hepatic lipid concentration. Sitosterol stearate demonstrated the highest level of net intestinal hydrolysis, whereas sitostanol and stigmasterol stearate equivalently demonstrated the lowest. The cholesterol-lowering effect in liver - but not plasma - and the limited presence of fecal free sterols indicate that intact (unhydrolyzed) phytosterol stearates may impact cholesterol metabolism by mechanisms unrelated to the role of free phytosterols. The consumption of phytosterol esters at $2.5 \%$ of the diet elicited only modest impacts on cholesterol metabolism, although sitosterol stearate had a slightly greater therapeutic impact by lowering liver free cholesterol and increasing esterified and total neutral sterol fecal excretion, possibly due to a greater level of intestinal hydrolysis.
\end{abstract}

Keywords: atherosclerosis, hamsters, cholesterol, cholesterol esterase, low-density lipoprotein, phytosterol ester, plant stanol, plant sterol, stearic acid

Abbreviations: BW, body weight; GC, gas chromatography; HDL, high-density lipoprotein; LDL, low-density lipoprotein; non-HDL, non-high-density lipoprotein; PSE, phytosterol stearate ester

\section{Introduction}

Atherosclerosis is the major cause of stroke and coronary heart disease, 2 prevalent cardiovascular diseases. Individuals with elevated plasma low-density lipoprotein (LDL) cholesterol concentrations are at a higher risk for atherosclerotic plaque development [1]. Both free and fatty acid-esterified phytosterols decrease serum
LDL cholesterol [2] and therefore reduce atherosclerosis disease risk. Because fatty acids have lipid-modulating effects, specific combinations of free fatty acids and phytosterols may positively or negatively affect therapeutic efficacy. Furthermore, certain phytosterols may be more efficacious based on structural features.

The impact of individual fatty acids on phytosterol ester treatment efficacy has been examined in previous 
studies. Fish oil phytosterol esters have demonstrated equal effectiveness as sunflower oil phytosterol esters in lowering LDL cholesterol but have the added benefit of reducing plasma triglycerides [3], indicating that the fish oil phytosterol esters maintain the favorable therapeutic effects of both the fatty acid and the phytosterol [4]. Phytosterols esterified to stearate-enriched fatty acid mixtures have demonstrated an ability to decrease LDL cholesterol in humans [5] and a superior plasma nonhigh-density lipoprotein (non-HDL) cholesterol-lowering efficacy compared with linoleate-enriched esters in hamsters [6]. Liberated stearic acid from phytosterol stearate ester (PSE) hydrolysis in the intestine may produce this enhanced efficacy due to the neutral [7] or lowering [8] effect of stearic acid on LDL cholesterol in comparison to other saturated fatty acids. Although the decrease in non-HDL shown in hamsters fed a $0.05 \%(\mathrm{~g} / \mathrm{g})$ cholesterol diet [8] may disappear at higher dietary cholesterol intake levels [9], stearic acid does increase fecal neutral sterol excretion [10], the major method of systemic cholesterol elimination [11]. Because stearic acid may also decrease bile acid hydrophobicity [8] and increase both cholesterol 7a-hydroxylase activity [8] and fecal bile acid excretion [10], phytosterols esterified to stearic acid may retain these beneficial impacts on cholesterol metabolism. In a previous hamster study, consumption of stearate-enriched phytosterol esters caused a greater decrease in non-HDL cholesterol than a comparable mixture of unesterified stearic acid and free phytosterols [12], suggesting that the beneficial effects of phytosterol stearates may occur through another mechanism in which complete hydrolysis may not be desirable.

Although the impact of the fatty acid component of phytosterol esters has been studied, the effect of the specific phytosterol incorporated has not been fully elucidated. Mattson and coworkers [13] demonstrated equivalent reductions in cholesterol absorption in rats fed sitosterol, campesterol, and stigmasterol oleates. However, the data may not reflect phytosterol ester efficacy in humans because of the use of a less sensitive animal model $[11,14]$ and a triolein emulsion rather than a hypercholesterolemic diet. Based on the hypocholesterolemic nature of stearic acid, we tested the hypothesis that PSEs containing different sterol moieties (sitosterol, sitostanol, or stigmasterol) produce different effects on cholesterol metabolism in male Syrian hamsters fed a high-cholesterol, high-saturated-fat diet. Sitosterol, stigmasterol, and campesterol are among the most abundant plant sterols in nature [15] and therefore the most readily available for affordable incorporation into phytosterol esters. Campesterol was not investigated because of its excessive cost and higher level of systemic absorption $[16,17]$. Although the data remain debatable, systemically absorbed plant sterols may increase atherosclerosis risk [18], thus decreasing the therapeutic attractiveness of campesterol. Sitosterol contains a double bond at carbon 5 , whereas stigmasterol contains double bonds at carbons 5 and 22. By focusing the current investigation on sitosterol, stigmasterol, and sitostanol (the saturated phytos- terol derived from hydrogenation of either sitosterol or stigmasterol), we examined the impact of steroid ring and side chain desaturation in PSE on therapeutic efficacy within Syrian hamsters fed an atherogenic diet.

\section{Methods and materials}

\subsection{Hamsters}

Thirty-nine male Syrian hamsters (Charles River Laboratories, Wilmington, Mass, USA) with body masses ranging from 56 to $70 \mathrm{~g}$ were divided into experimental groups of 9 to 10 hamsters and placed in individual polycarbonate cages with sawdust bedding. The hamsters were fed ad libitum for 28 days and maintained in a humidity-controlled $25^{\circ} \mathrm{C}$ room with a 12-hour light/ dark cycle.

Hamster feed intake and body weight (BW) records were maintained weekly. During week 3, fecal matter was collected for 4 days after dual-isotope dose administration in soybean oil for cholesterol absorption measurement. Bedding was collected for 7-day pooled fecal acidic and neutral sterol excretion analyses at the end of week 4 . On day 28, nonfasted hamsters were euthanized with $\mathrm{CO}_{2}$, the thoracic cavity was exposed by incision, and blood was collected by cardiac puncture using 10 -mL syringes before transfer to $10 \mathrm{mg}$ EDTA-containing tubes on ice. Plasma was isolated by centrifugation at $1000 \mathrm{~g}$ for 30 minutes at $4^{\circ} \mathrm{C}$ and stored at $-80^{\circ} \mathrm{C}$ until analyzed. Whole livers were excised, weighed, and frozen in liquid nitrogen before storage at $-80^{\circ} \mathrm{C}$. All procedures were approved by the Institutional Animal Care and Use Committee of the University of Nebraska.

\subsection{Experimental diets}

The hamsters were fed a purified, atherogenic AIN-93M diet high in cholesterol $(1.2 \mathrm{~g} / \mathrm{kg})$ and coconut oil $(80$ $\mathrm{g} / \mathrm{kg}$ ) [19]. This diet has been shown to induce similar metabolic responses and comparative pathologies to humans [20, 21]. All 4 diets contained the following (in $g$ per $\mathrm{kg}$ ): cornstarch, 379.5; dextrinized cornstarch, 155.0; casein, 140.0; sucrose, 100.0; coconut oil, 80.0; soybean oil, 20.0; cellulose, 40.0; soluble fiber (guar gum), 10.0; cholesterol, 1.2; AIN-93 mineral mix, 35.0; AIN-93 vitamin mix, 10.0; L-cystine, 1.8; and choline bitartrate, 2.5 . The PSE diets contained $25.0 \mathrm{~g} / \mathrm{kg}$ of each respective phytosterol ester, whereas the control diet contained an additional $25.0 \mathrm{~g} / \mathrm{kg}$ of cornstarch. The phytosterol purity of the administered PSE was determined in triplicate using gas chromatography (GC) analysis after saponification, yielding purity values of $96.8 \% \pm 2.7 \%$ for sitostanol stearate, $98.5 \% \pm 0.2 \%$ for stigmasterol stearate, and $76.3 \% \pm 1.3 \%$ for sitosterol stearate (Table 1 ). Large amounts of sitosterol per se are difficult and expensive to obtain in higher purities; therefore, we determined that $76.3 \%$ purity of sitosterol stearate was sufficient to proceed with the study. The PSEs were 
Table 1. Phytosterol stearate treatment purity and composition

\begin{tabular}{lrrr}
\hline Phytosterol & $\begin{array}{l}\text { Sitostanol } \\
\text { stearate }\end{array}$ & $\begin{array}{l}\text { Stigmasterol } \\
\text { stearate }\end{array}$ & \multicolumn{1}{c}{$\begin{array}{l}\text { Sitosterol } \\
\text { stearate }\end{array}$} \\
\hline & $\%$ & & \\
Campesterol & $1.6 \pm 1.4^{\mathrm{b}}$ & $0.1 \pm 0.2^{\mathrm{b}}$ & $9.5 \pm 0.3^{\mathrm{a}}$ \\
Stigmasterol & $1.5 \pm 1.3^{\mathrm{b}}$ & $98.5 \pm 0.2^{\mathrm{a}}$ & $0.2 \pm 0.3^{\mathrm{b}}$ \\
Sitosterol & $0.0 \pm 0.0^{\mathrm{b}}$ & $1.0 \pm 0.5^{\mathrm{b}}$ & $76.3 \pm 1.3^{\mathrm{a}}$ \\
Sitostanol & $96.8 \pm 2.7^{\mathrm{a}}$ & $0.4 \pm 0.5^{\mathrm{c}}$ & $14.0 \pm 1.2^{\mathrm{b}}$ \\
\hline
\end{tabular}

Treatment purity denotes the percentage of the treatment phytosterol within the mixture. Values are means $\pm \mathrm{SD} ; \mathrm{n}=3$. Means within a row having different superscripts $(\mathrm{a}, \mathrm{b})$ are statistically different $(P<.05)$.

synthesized from free phytosterols and stearoyl chloride purchased from TCI America (Portland, Ore, USA) as previously described [22]. The AIN-93 mineral and vitamin mixes, casein, dextrinized cornstarch, and fibers were purchased from Dyets, Inc (Bethlehem, Pa, USA); choline bitartrate, L-cystine, and cholesterol were from Sigma Chemicals (St Louis, Mo, USA); and cornstarch, sucrose, and soybean oil were from a local grocery store. Diets were stored at $-80^{\circ} \mathrm{C}$ before use.

\subsection{Cholesterol absorption assay}

$\left[{ }^{14} \mathrm{C}\right]$-Cholesterol and $\left[{ }^{3} \mathrm{H}\right]$-sitostanol were mixed into soybean oil for administration to hamsters as described by Turley et al [23] and modified by our laboratory [10, 24]. On 2 consecutive days, the dual-isotopic mixture was administered to each animal by gavage; and feces were collected 4 days following the initial dose. Cholesterol absorption $=\left[\left(\left[{ }^{14} \mathrm{C}\right] /\left[{ }^{3} \mathrm{H}\right]\right.\right.$ in dose $-\left[{ }^{14} \mathrm{C}\right] /\left[{ }^{3} \mathrm{H}\right]$ in feces) $/\left(\left[{ }^{14} \mathrm{C}\right] /\left[{ }^{3} \mathrm{H}\right]\right.$ in dose $\left.)\right] \times 100 \%$. Radiolabeled $4-\left[{ }^{14} \mathrm{C}\right]-$ cholesterol and 5,6- $\left[{ }^{3} \mathrm{H}\right]$-sitostanol were purchased from American Radiolabeled Chemicals (St Louis, Mo, USA).

\subsection{Plasma lipid analyses}

Plasma total cholesterol concentration was measured enzymatically as previously described [25] using regents purchased from Roche Diagnostics (Indianapolis, Ind, USA). The HDL cholesterol quantification was performed using the total cholesterol assay after precipitation of apolipoprotein-B-containing lipoproteins (Thermo Electron Corp, Melbourne, Australia). Non-high-density lipoprotein cholesterol was calculated as the difference between the total cholesterol and HDL cholesterol.

\subsection{Liver lipid quantifications}

Liver lipids were extracted using the Folch extraction procedure [26] as previously described [24]. Triton X-100 ( $10 \%$ in chloroform; vol/vol) was added to liver lipid extracts to solubilize the lipids as previously described [25]. Quantification of total cholesterol, free cholesterol, phospholipids, and triglycerides were performed in duplicate. Total cholesterol and triglyceride reagents were purchased from Roche Diagnostics (Indianapolis, Ind, USA); the free cholesterol and phospholipid reagents were purchased from Wako Chemicals (Richmond, Va, USA).
Liver esterified cholesterol was calculated as the difference between total and free cholesterol.

\subsection{Fecal bile acid analysis}

Bile acids were quantitatively extracted from feces using the chloroform/methanol (2:1, vol/vol) procedure of Folch et al [26] and quantified using the $3 a$-hydroxysteroid dehydrogenase method as previously described [27]. $\beta$-NAD, CAPS, cholic acid, and $3 a$-hydroxysteroid dehydrogenase were purchased from Sigma-Aldrich (St Louis, Mo, USA).

\subsection{Fecal free and esterified sterol analyses}

Fecal neutral sterols (cholesterol, dihydrocholesterol, coprostanol, and coprostanone) and phytosterols (brassicasterol, campesterol, stigmasterol, sitosterol, and sitostanol) were quantitatively extracted [26] after the addition of the internal standard $5 a$-cholestane. Free sterols were measured via direct lipid extract GC analysis [10], whereas esterified sterols were quantified using a modification of the thin-layer chromatography protocol published by Nissinen et al [28]. Briefly, aliquots of the lipid extracts were dried under nitrogen, dissolved in $50 \mu \mathrm{L}$ of chloroform, and transferred to a 1 in-wide band on Whatman AL-SIL G thin-layer chromatography plates (aluminumbacked, $60 \AA$ silica, $250 \mu \mathrm{m} \times 20 \times 20 \mathrm{~cm}$; catalog no. 4420 221) before 45 minutes of heptane/diethyl ether (50:50, vol/vol) mobile phase exposure. The regions corresponding to esterified sterol were extracted into chloroform, saponified, and analyzed by GC [10]. All GC analyses were performed on an AT-5 capillary column (Alltech, Deerfield, Ill, USA) with helium as the carrier gas, an inlet temp of $270^{\circ} \mathrm{C}$, and a flame ionizing detector temperature of $300^{\circ} \mathrm{C}$. The temperature program consisted of initial 1-minute hold at $270^{\circ} \mathrm{C}$ followed by a $15.0^{\circ} \mathrm{C} / \mathrm{min}$ temperature ramp to a final 14 -minute hold at $300^{\circ} \mathrm{C}$.

\subsection{Statistical analyses}

Statistical 1-way analyses of variance were performed using the GLM procedure and the simulated adjustment for multiple comparisons using the "/pdiff" option of "lsmeans" in SAS 9.0 (SAS Institute, Cary, NC, USA). The simulated adjustment was used to account for the different number of experimental units within each treatment group (control, $\mathrm{n}=9$; PSE treatments, $\mathrm{n}$ $=10) . P<.05$ was considered significant.

\section{Results}

\subsection{BWs and food intake}

Weekly hamster BWs and cumulative BW gain did not significantly differ between diets during any of the weeks, and the final average BW of all the hamsters in the study was $118 \pm 1.4 \mathrm{~g}$. Food intake measurements 
obtained weekly did not differ among the treatments for week 1, 2, or 3 (Table 2). During week 4, the control group had higher food intake compared with the sitostanol and stigmasterol stearate groups. However, the weekly average food intake was not significantly different among any of the groups.

\subsection{Intestinal cholesterol absorption}

Cholesterol absorption efficiency was equivalent among the PSE treatment groups (sitostanol stearate, 59.9\% \pm $3.0 \%$; stigmasterol stearate, $63.0 \% \pm 2.0 \%$; and sitosterol stearate, $66.2 \% \pm 3.0 \%$ ) and did not differ significantly from the control $(61.6 \% \pm 3.0 \%)$.

\subsection{Plasma cholesterol and liver lipid concentrations}

Plasma cholesterol concentrations were unchanged by any of the treatments in comparison to the control after 4 weeks (Table 3). However, differences were observed in liver free cholesterol concentrations (Table 4). The sitostanol and sitosterol stearate groups equivalently had the lowest liver free cholesterol compared with both the control and the stigmasterol stearate groups, which did not differ. No differences were observed in liver esterified cholesterol, triglycerides, phospholipids, or liver wet weights among the treatment groups (Table 4).

\subsection{Fecal output and fecal sterol excretion}

Fecal output was significantly higher in the sitostanol stearate $\left(0.979 \pm 0.02 \mathrm{~g} \mathrm{~d}^{-1} 100 \mathrm{~g}^{-1} \mathrm{BW}\right)$ and sitosterol stearate $\left(0.971 \pm 0.05 \mathrm{~g} \mathrm{~d}^{-1} 100 \mathrm{~g}^{-1} \mathrm{BW}\right)$ groups compared with the control group $\left(0.830 \pm 0.03 \mathrm{~g} \mathrm{~d}^{-1} 100 \mathrm{~g}^{-1} \mathrm{BW}\right)$. Stigmasterol stearate fecal output $\left(0.931 \pm 0.03 \mathrm{~g} \mathrm{~d}^{-1} 100\right.$ $\mathrm{g}^{-1} \mathrm{BW}$ ) did not differ significantly from any other group. Bile acid excretion did not differ significantly, ranging from $1.29 \pm 0.09 \mu \mathrm{mol} \mathrm{d}^{-1} 100 \mathrm{~g}^{-1}$ BW (sitosterol stearate) to $1.53 \pm 0.06 \mu \mathrm{mol} \mathrm{d}^{-1} 100 \mathrm{~g}^{-1} \mathrm{BW}$ (stigmasterol stearate) (Table 5). Whereas free neutral sterol excretion was similar among the groups, esterified and total neutral sterol excretion differed significantly. The sitosterol stearate treatment elicited a higher esterified neutral sterol excretion compared with the other diets, which did not differ. Sitosterol stearate total neutral sterol excretion was significantly higher than both the control and the stigmasterol stearate treatments but did not differ from the sitostanol stearate treatment despite a strong trend $(P=.056)$. Sitosterol stearate elicited the highest percentage esterified neutral sterol excretion, whereas the stigmasterol and sitostanol stearate treatments did not differ despite the presence of an elevated percentage esterified neutral sterol excretion in the stigmasterol stearate treatment compared with the control (Table 5).

Free phytosterol excretion was equivalent and elevated in the stigmasterol and sitosterol stearate groups compared with the control and the sitostanol stearate groups, which did not differ (Table 5). Esterified phytosterol excretion did not differ among the PSE treatments
Table 2. Food intake

\begin{tabular}{lcccc}
\hline & Control & $\begin{array}{l}\text { Sitostanol } \\
\text { stearate }\end{array}$ & $\begin{array}{l}\text { Stigmasterol } \\
\text { stearate }\end{array}$ & $\begin{array}{l}\text { Sitosterol } \\
\text { stearate }\end{array}$ \\
\hline \multicolumn{2}{c}{$\mathrm{g} / \mathrm{d}$} & & & \\
Week 1 & $8.2 \pm 0.5$ & $8.7 \pm 0.7$ & $9.4 \pm 1.0$ & $8.0 \pm 0.4$ \\
Week 2 & $12.0 \pm 0.9$ & $11.5 \pm 1.0$ & $10.9 \pm 0.5$ & $11.1 \pm 0.7$ \\
Week 3 & $11.3 \pm 0.6$ & $12.2 \pm 0.7$ & $13.2 \pm 0.4$ & $12.2 \pm 0.4$ \\
Week 4 & $7.5 \pm 0.8^{\mathrm{a}}$ & $4.2 \pm 0.5^{\mathrm{b}}$ & $3.2 \pm 0.6^{\mathrm{b}}$ & $5.3 \pm 0.4^{\mathrm{a}, \mathrm{b}}$ \\
Average & $9.7 \pm 0.6$ & $9.2 \pm 0.6$ & $9.2 \pm 0.5$ & $9.2 \pm 0.3$ \\
\hline
\end{tabular}

Values are means \pm SEM; $n=9$ to 10 . Means within a row having different superscripts $\left({ }^{\mathrm{a}, \mathrm{b}}\right)$ are statistically different $(P<.05)$.

Table 3. Plasma lipid concentrations

\begin{tabular}{lcccc}
\hline & Control & $\begin{array}{l}\text { Sitostanol } \\
\text { stearate }\end{array}$ & $\begin{array}{l}\text { Stigmasterol } \\
\text { stearate }\end{array}$ & $\begin{array}{l}\text { Sitosterol } \\
\text { stearate }\end{array}$ \\
\hline \multicolumn{4}{c}{$\mathrm{mmol} / \mathrm{L}$} \\
$\begin{array}{l}\text { Total cholesterol } \\
\text { Non-HDL } \\
\text { cholesterol }\end{array}$ & $6.14 \pm 0.23$ & $5.67 \pm 0.34$ & $5.87 \pm 0.21$ & $5.42 \pm 0.26$ \\
HDL cholesterol & $2.31 \pm 0.17$ & $2.21 \pm 0.10$ & $2.36 \pm 0.10$ & $2.09 \pm 0.10$ \\
\hline
\end{tabular}

Values are means \pm SEM; $n=9$ to 10 . No treatment differences were detected.

Table 4. Liver weight and lipid concentrations

\begin{tabular}{|c|c|c|c|c|}
\hline & Control & $\begin{array}{l}\text { Sitostanol } \\
\text { stearate }\end{array}$ & $\begin{array}{l}\text { Stigmasterol } \\
\text { stearate }\end{array}$ & $\begin{array}{l}\text { Sitosterol } \\
\text { stearate }\end{array}$ \\
\hline & $\mu \mathrm{mol} / \mathrm{g}$ & & & \\
\hline Free cholesterol & $4.7 \pm 0.1^{\mathrm{a}}$ & $4.2 \pm 0.1^{b}$ & $4.5 \pm 0.0^{\mathrm{a}}$ & $4.2 \pm 0.1^{b}$ \\
\hline $\begin{array}{l}\text { Esterified } \\
\text { cholesterol }\end{array}$ & $13.1 \pm 2.1$ & $9.5 \pm 1.8$ & $14.4 \pm 2.0$ & $11.5 \pm 2.2$ \\
\hline Triglyceride & $5.0 \pm 0.3$ & $5.4 \pm 0.4$ & $4.6 \pm 0.3$ & $5.6 \pm 0.4$ \\
\hline Phospholipid & $13.1 \pm 0.3$ & $12.6 \pm 0.3$ & $12.8 \pm 0.3$ & $12.5 \pm 0.3$ \\
\hline Liver weight & $\begin{array}{c}\mathrm{g} / 100 \mathrm{~g} \mathrm{c} \\
5.99 \pm 0 .\end{array}$ & $\begin{array}{l}\text { BW } \\
35.97 \pm 0.17\end{array}$ & $5.73 \pm 0.14$ & $5.92 \pm 0.10$ \\
\hline
\end{tabular}

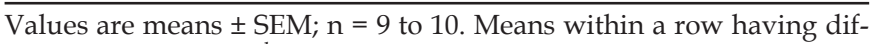
ferent superscripts $(\mathrm{a}, \mathrm{b})$ are statistically different $(P<.05)$.

but was lowest in the control group. Total phytosterol excretion was equivalently greater among the PSE treatments compared with the control, reflecting the intended study design.

The isolated effects of added dietary PSE were examined to elucidate the excretion of the specific treatment phytosterol administered (Table 5). Sitosterol stearate elevated free treatment phytosterol excretion compared with sitostanol stearate but not stigmasterol stearate. Sitostanol stearate elicited a higher esterified treatment phytosterol excretion than the equivalent stigmasterol and sitosterol stearate treatments. Total treatment phytosterol excretion was higher in the sitostanol stearate group compared with both the stigmasterol and sitosterol stearate groups, which did not differ. The percentage free treatment phytosterol to total treatment phytosterol was used as an indirect measure of net hydrolysis (Table 5). Sitosterol stearate elicited a greater net hydrolysis than the equivalent sitostanol and stigmasterol stearate treatments. The PSE free phytosterol equivalent dose was cal- 
Table 5. Fecal sterol excretion

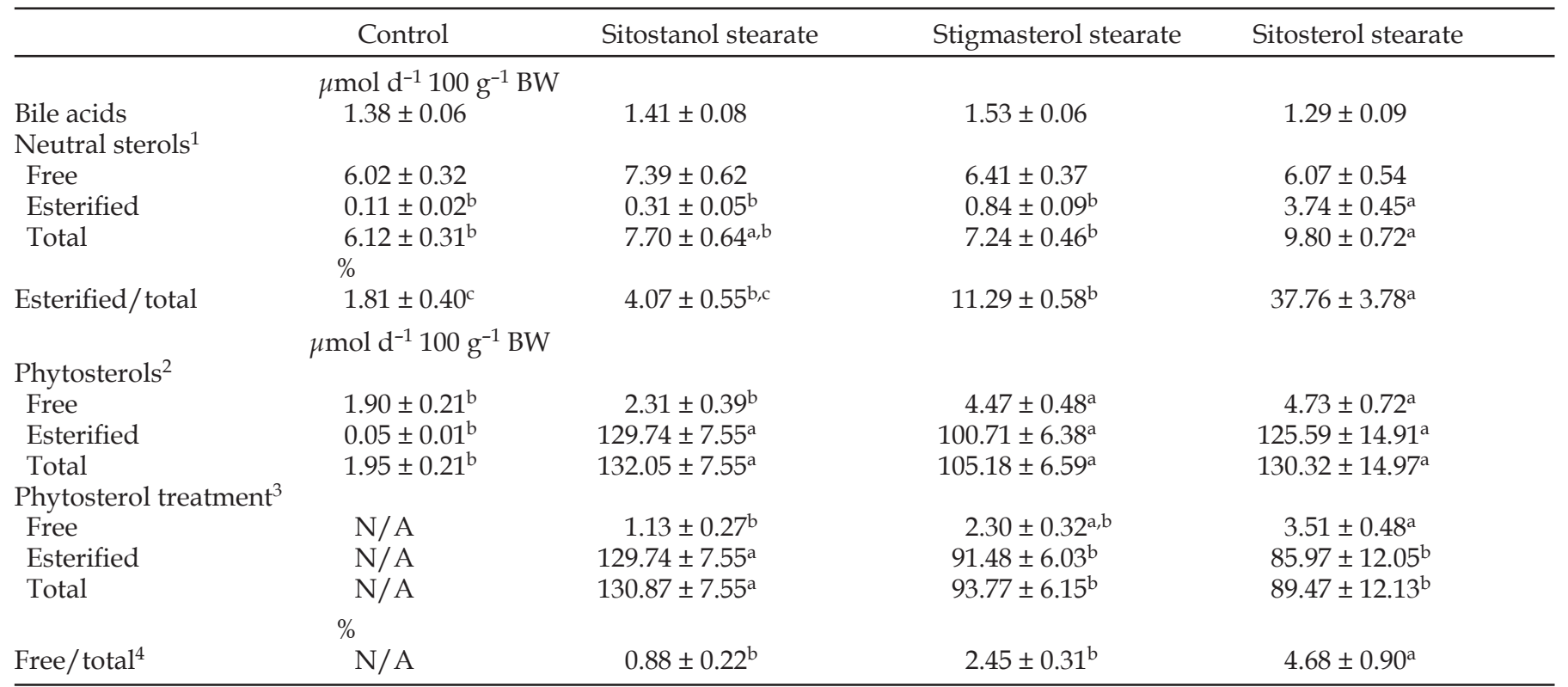

Values are means \pm SEM; $\mathrm{n}=9$ to 10 . N/A indicates not applicable because of no added phytosterols in diet. Means within a row having different superscripts $\left({ }^{\mathrm{a}, \mathrm{b}, \mathrm{c}}\right)$ are statistically different $(P<.05)$.

${ }^{1}$ Sum of cholesterol, dihydrocholesterol, coprostanol, and coprostanone.

${ }^{2}$ Sum of brassicasterol, campesterol, stigmasterol, sitosterol, and sitostanol.

${ }^{3}$ Phytosterol treatment indicates quantification of the specific treatment phytosterol only.

${ }^{4}$ Free treatment phytosterol to total treatment phytosterol ratio is referred to as net hydrolysis.

culated from the net hydrolysis data with the following formula: free phytosterol equivalent dose $=[$ free $/$ total treatment phytosterol excretion $\%] \times[2.5 \%(\mathrm{~g} / \mathrm{g})$ dose $\times$ phytosterol molecular weight $\%$ of PSE molecular weight] $\times 100 \%$. The free phytosterol equivalent doses $(\mathrm{g} / \mathrm{g})$ were $0.069 \%$ (sitosterol), $0.036 \%$ (stigmasterol), and $0.013 \%$ (sitostanol) for the respective treatments.

\section{Discussion}

Results of this study indicated that phytosterol esters containing different sterol moieties (sitosterol, sitostanol, or stigmasterol) but the same fatty acid moiety (stearic acid) produced different, albeit modest, effects on cholesterol metabolism in male Syrian hamsters. Liver free cholesterol concentration was significantly lower in hamsters fed sitosterol and sitostanol stearate compared with those fed stigmasterol stearate, whereas only sitosterol stearate caused significantly greater fecal neutral sterol excretion relative to sitostanol and stigmasterol stearate treatment. Sitosterol stearate was also hydrolyzed in the intestine to a greater extent than the other PSE treatments, indicating that the sterol moiety interacts differently with hydrolytic enzymes. These results support the hypothesis, at least to some extent, that the sterol component of PSE exerts unique effects on certain aspects of cholesterol metabolism. In contrast, no treatment differences were detected in intestinal cholesterol absorption, plasma cholesterol measurements, or fecal bile acid excretion. Although sitosterol stearate caused the highest amount of fecal neutral sterol excretion and lowest liver free cholesterol, these changes were not accompanied by lower plasma cholesterol; therefore, in our short-term feeding experiment, sitosterol stearate esters appeared to exert no greater impact on health benefits than PSE containing different sterols.

Our data are consistent with phytosterol-induced increases in fecal neutral sterol excretion previously demonstrated [29], but we did not observe the expected decrease in intestinal cholesterol absorption or plasma cholesterol reported in previous studies [6,12]. Whereas stearic acid-enriched phytosterol esters fed to hamsters at $5 \%$ of the diet lowered non-HDL cholesterol [6], our 2.5\% PSE treatments did not lower plasma total, nonHDL, or HDL cholesterol. In contrast, hamsters fed a much lower amount $(0.24 \%$ of the diet) of phytosterol esters made with unsaturated fatty acids (canola oil) exhibited reductions in plasma non-HDL cholesterol [30, 31]. We recently reported that phytosterol esters containing unsaturated fatty acids (oleate) are hydrolyzed in vitro to a much greater extent than phytosterol esters containing saturated fatty acids [22], suggesting that hydrolysis and liberation of free sterol may be important factors in decreasing cholesterol absorption and/or plasma non-HDL cholesterol concentration.

The primary mechanism by which phytosterols lower cholesterol is thought to be displacement of cholesterol from micelles by free phytosterols [32] and phytosterols hydrolyzed from phytosterol esters [33]. We recently observed that about $90 \%$ of phytosterol oleate esters are hydrolyzed in vivo (unpublished observa- 
tions), whereas the current study indicated that a maximum of $4.68 \%$ of sitosterol stearate ester is hydrolyzed. When fed PSE at $2.5 \%$ of the diet-assuming approximately $5 \%$ hydrolysis and the fact that the sterol moiety is $60 \%$ of PSE mass - the maximum amount of free phytosterol liberated from hydrolysis would be equivalent to feeding free phytosterol at $0.075 \%$ of the diet. In comparison, feeding $0.24 \%$ phytosterol esters made with unsaturated fatty acids [30, 31], assuming $90 \%$ hydrolysis, would be equivalent to feeding free phytosterol at $0.13 \%$ of the diet. If cholesterol-lowering efficacy is indeed dependent on the presence of free phytosterol, then our treatment using stearate esters may have had the disadvantage of resisting hydrolysis and limiting the amount of free phytosterol.

The current results seem to contradict our previous study demonstrating significant cholesterol lowering in hamsters consuming PSE at $5 \%$ of the diet $[6,12]$. However, because intact phytosterol esters do not incorporate into micelles or affect cholesterol solubility within mixed micelles in vitro [34], unhydrolyzed phytosterol esters may affect cholesterol absorption independent of micelles by creating a lipid phase in which cholesterol becomes trapped. Indirect evidence for this can be inferred by decreased cholesterol absorption in triglyceride lipase knockout mice fed a high-cholesterol, high-fat diet [35]. As we previously observed, the superior cholesterol lowering of presumably intact 5\% stearate-enriched phytosterol esters compared with a completely hydrolyzed treatment (consumed as $3.0 \%$ free phytosterols and $2.0 \%$ stearic acid) [12] supports the presence of a separate phytosterol stearate mechanism.

In the present study, sitosterol stearate esters elicited a slightly greater positive effect on cholesterol metabolism than the other PSEs consumed at $2.5 \%$ of the diet by increasing fecal neutral sterol excretion and lowering liver free cholesterol. Our data suggest that the cholesterol-lowering abilities of PSEs may involve mechanisms in addition to simple displacement of cholesterol from micelles. When consumed by hamsters at $2.5 \%$ of the diet, sitosterol stearate esters appeared to be the most efficacious PSE despite only a modest impact upon cholesterol metabolism. At this level of intake, the short-term health benefits of sitosterol stearate esters appear to be minimal, although the metabolic impact of PSE long-term treatment should be investigated.

Acknowledgments - We wish to thank Dr Andrew Brown for his scientific contributions and Trevor Carden and Mary Peetz for their help with diet preparation, animal handling, and sample analysis. The research was supported by U.S. Department of Agriculture-National Research Initiative (National Institute of Food and Agriculture) competitive grant no. 2007-35200-18298 and by the University of Nebraska Agricultural Research Division with funds provided through the Hatch Act.

\section{References}

[1] National Cholesterol Education Program, Third report of the National Cholesterol Education Program (NCEP) expert panel on detection, evaluation, and treatment of high blood cholesterol in adults (Adult Treatment Panel III) final report. Circulation, 106 (2002), pp. 3143-3421.

[2] I. Demonty, R.T. Ras, H.C. van der Knaap, G.S. Duchateau, L. Meijer and P.L. Zock, et al. Continuous dose-response relationship of the LDL-cholesterol-lowering effect of phytosterol intake. J Nutr, 139 (2009), pp. 271-284.

[3] I. Demonty, Y.M. Chan, D. Pelled and P.J. Jones, Fish-oil esters of plant sterols improve the lipid profile of dyslipidemic subjects more than do fish-oil or sunflower oil esters of plant sterols. Am J Clin Nutr, 84 (2006), pp. 1534-1542.

[4] M.A. Micallef and M.L. Garg, The lipid-lowering effects of phytosterols and (n-3) polyunsaturated fatty acids are synergistic and complementary in hyperlipidemic men and women. J Nutr, 138 (2008), pp. 1086-1090.

[5] T.P. Carr, K.L. Krogstrand, V.L. Schlegel and M.L. Fernandez, Stearate-enriched plant sterol esters lower serum LDL cholesterol concentration in normo- and hypercholesterolemic adults. J Nutr, 139 (2009), pp. 1445-1450.

[6] H.E. Rasmussen, D.M. Guderian, C.A. Wray, P.H. Dussault, V.L. Schlegel and T.P. Carr, Reduction in cholesterol absorption is enhanced by stearate-enriched plant sterol esters in hamsters. J Nutr, 136 (2006), pp. 2722-2727.

[7] S. Grundy, Influence of stearic acid on cholesterol metabolism relative to other long-chain fatty acids. Am J Clin Nutr, 60 (1994), pp. 986S-990S.

[8] R.L. Cowles, J.Y. Lee, D.D. Gallaher, C.L. Stuefer-Powell and T.P. Carr, Dietary stearic acid alters gallbladder bile acid composition in hamsters fed cereal-based diets. J Nutr, 132 (2002), pp. 3119-3122.

[9] K. Imaizumi, K. Abe, C. Kuroiwa and M. Sugano, Fat containing stearic acid increases fecal neutral steroid excretion and catabolism of low density lipoproteins without affecting plasma cholesterol concentration in hamsters fed a cholesterol-containing diet. J Nutr, 123 (1993), pp. 1693-1702.

[10] C.L. Schneider, R.L. Cowles, C.L. Stuefer-Powell and T.P. Carr, Dietary stearic acid reduces cholesterol absorption and increases endogenous cholesterol excretion in hamsters fed cereal-based diets. J Nutr, 130 (2000), pp. 1232-1238.

[11] J. Dietschy, S. Turley and D. Spady, Role of liver in the maintenance of cholesterol and low density lipoprotein homeostasis in different animal species, including humans. J Lipid Res, 34 (1993), pp. 1637-1659.

[12] D.M. Guderian, H.E. Rasmussen, C.A. Wray, P.H. Dussault and T.P. Carr, Cholesterol-lowering properties of plant sterols esterified with beef tallow fatty acids in hamsters. Nutr Res, 27 (2007), pp. 283-288.

[13] F.H. Mattson, R.A. Volpenhein and B.A. Erickson, Effect of plant sterol esters on the absorption of dietary cholesterol. J Nutr, 107 (1977), pp. 1139-1146.

[14] J.D. Horton, J.A. Cuthbert and D.K. Spady, Regulation of hepatic 7-hydroxylase expression and response to dietary cholesterol in the rat and hamster. J Biol Chem, 270 (1995), pp. 5381-5387.

[15] A.H. Lichtenstein and R.J. Deckelbaum, AHA science advisory. Stanol/sterol ester-containing foods and blood cholesterol levels. A statement for healthcare professionals from the Nutrition Committee of the Council on Nutri- 
tion, Physical Activity, and Metabolism of the American Heart Association. Circulation, 103 (2001), pp. 1177-1179.

[16] D. Lutjohann, I. Bjorkhem, U.F. Beil and K. von Bergmann, Sterol absorption and sterol balance in phytosterolemia evaluated by deuterium-labeled sterols: effect of sitostanol treatment. J Lipid Res, 36 (1995), pp. 1763-1773.

[17] R.E. Ostlund, J.B. McGill, C.M. Zeng, D.F. Covey, J. Stearns and W.F. Stenson, et al. Gastrointestinal absorption and plasma kinetics of soy delta 5-phytosterols and phytostanols in humans. Am J Physiol Endocrinol Metab, 282 (2002), pp. E911-E916.

[18] O. Weingärtner, M. Böhm and U. Laufs, Controversial role of plant sterol esters in the management of hypercholesterolaemia. Eur Heart J, 30 (2009), pp. 404-409.

[19] P.G. Reeves, F.H. Nielsen and G.C. Fahey, AIN-93 purified diets for laboratory rodents: final report of the American Institute of Nutrition Ad Hoc Writing Committee on the Reformulation of the AIN-76a Rodent Diet. J Nutr, 123 (1993), pp. 1939-1951.

[20] A. Nistor, A. Bulla, D.A. Filip and A. Radu, The hyperlipidemic hamster as a model of experimental atherosclerosis. Atherosclerosis, 68 (1987), pp. 159-173.

[21] C.S. Pien, W.P. Davis, A.J. Marone and T.L. Foxall, Characterization of diet induced aortic atherosclerosis in Syrian F1B hamsters. J Exp Anim Sci, 42 (2002), pp. 65-83.

[22] A.W. Brown, J. Hang, P.H. Dussault and T.P. Carr, Plant sterol and stanol substrate specificity of pancreatic cholesterol esterase. J Nutr Biochem, 21 (2010), pp. 736-740.

[23] S.D. Turley, B.P. Daggy and J.M. Dietschy, Psyllium augments the cholesterol-lowering action of cholestyramine in hamsters by enhancing sterol loss from the liver. Gastroenterology, 107 (1994), pp. 444-452.

[24] G. Cai and T.P. Carr, Biliary cholesterol and bile acid excretion do not increase in hamsters fed cereal-based diets containing cholesterol. Metabolism, 48 (1999), pp. 400-405.

[25] T.P. Carr, C.J. Andresen and L.L. Rudel, Enzymatic determination of triglyceride, free cholesterol, and total cholesterol in tissue lipid extracts. Clin Biochem, 26 (1993), pp. 39-42.
[26] J. Folch, M. Lees and G.H. Sloane Stanley, A simple method for the isolation and purification of total lipides from animal tissues. J Biol Chem, 226 (1957), pp. 497-509.

[27] M.J. Sheltawy and M.S. Losowsky, Determination of faecal bile acids by an enzymic method. Clin Chim Acta, 64 (1975), pp. 127-132.

[28] M. Nissinen, M. Vuoristo, H. Gylling and T. Miettinen, Respective hydrolysis and esterification of esterified and free plant stanols occur rapidly in human intestine after their duodenal infusion in triacyl- or diacylglycerol. Lipids, 42 (2007), pp. 603-612.

[29] T.P. Carr, R.M. Cornelison, B.J. Illston, C.L. Stuefer-Powell and D.D. Gallaher, Plant sterols alter bile acid metabolism and reduce cholesterol absorption in hamsters fed a beefbased diet. Nutr Res, 22 (2002), pp. 745-754.

[30] Y. Lin, G.W. Meijer, M.A. Vermeer and E.A. Trautwein, Soy protein enhances the cholesterol-lowering effect of plant sterol esters in cholesterol-fed hamsters. J Nutr, 134 (2004), pp. 143-148.

[31] E.A. Trautwein, C. Schulz, D.R. Rieckhoff, A. Kunath-Rau, H.F. Erbersdobler and W. Arjan de Groot, et al. Effect of esterified 4-desmethylsterols and -stanols or 4,4'-dimethylsterols on cholesterol and bile acid metabolism in hamsters. Brit J Nutr, 87 (2002), pp. 227-237.

[32] E.D. Jesch and T.P. Carr, Sitosterol reduces micellar cholesterol solubility in model bile. Nutr Res, 26 (2006), pp. 579-584.

[33] T.P. Carr, M.M. Ash and A.W. Brown, Cholesterol-lowering phytosterols: factors affecting their use and efficacy. Nutr Dietary Suppl, 2 (2010), pp. 59-72.

[34] A.W. Brown, J. Hang, P.H. Dussault and T.P. Carr, Phytosterol ester constituents affect micellar cholesterol solubility in model bile. Lipids, 45 (2010), pp. 855-862.

[35] D. Gilham, E.D. Labonte, J.C. Rojas, R.J. Jandacek, P.N. Howles and D.Y. Hui, Carboxyl ester lipase deficiency exacerbates dietary lipid absorption abnormalities and resistance to diet-induced obesity in pancreatic triglyceride lipase knockout mice. J Biol Chem, 282 (2007), pp. 24642-24649. 